\title{
ORTHOPEDIC ASSESSMENT OF THE HIPS IN NEWBORNS AFTER INITIAL PEDIATRIC SURVEY
}

\author{
AVALIAÇÃO ORTOPÉDICA DOS QUADRIS DE RECÉM-NASCIDOS \\ APÓS EXAME PEDIÁTRICO INICIAL ALTERADO
}

\author{
Felipe Chioro Gonzalez ${ }^{1}$, Felipe Fontes ${ }^{1}$, Guilherme de Albuquerque Souza Maia ${ }^{1}$, James Augusto Soares Ferro ${ }^{1}$, \\ DAVID LEITE FORTES ${ }^{1}$, DANIEL MENDES LEAL ${ }^{1}$
}

1. Santa Casa de Ribeirão Preto, Serviço de Ortopedia, Ribeirão Preto, SP, Brazil.

\begin{abstract}
Objective: To analyze and follow-up patients previously selected by pediatricians at the time of birth who presented altered initial physical examination results to identify the pathological changes in their hips. Methods: A prospective cohort study was conducted involving 34 newborns (68 hips) out of a total of 1273 live births; these infants were assessed within the first days of life as altered findings were noted in the initial examination by the pediatrician. The results of clinical and ultrasonographic examination performed using the GRAF method and of specific treatments were analyzed. Results: Of the 68 hips in 34 patients, 2 hips in 2 patients required intervention using the Pavlik harness for 8 weeks; a satisfactory treatment outcome was obtained in both cases. Conclusions: Despite the low orthopedic workload in medical courses, it was possible to identify data consistent with the literature, both in the presentation of clinical findings and in those that required treatment, indicating that an initial evaluation of all newborns is mandatory, especially those with risk factors. Level of evidence IV, case series.
\end{abstract}

Keywords: Hip Dislocation Congenital. Hip Dislocation. Infant newborns.

\section{RESUMO}

Objetivo: Analisar e acompanhar os pacientes previamente selecionados por pediatras desde o nascimento, em busca de alterações patológicas nos quadris, naqueles considerados com exame físico inicial alterado. Métodos: Estudo de coorte prospectivo, iniciado nos primeiros dias de vida, em 68 quadris de 34 recém-nascidos, de um total de 1.273 nascidos vivos no ano da pesquisa, devido a alguma alteração no exame inicial do pediatra. Primeiramente, foram utilizados exame clínico e ultrassonográfico, com o método de Graf, tendo sido instituído tratamento específico naqueles que se fizeram necessários. Resultados: Dos 68 quadris em 34 pacientes, dois quadris em dois pacientes distintos necessitaram de intervenção com uso do suspensório de Pavlik por 8 semanas, obtendo resultado satisfatório em ambos após o término do tratamento. Conclusão: Apesar da baixa carga horária da Ortopedia nos cursos de medicina, podem-se observar dados condizentes com a literatura, tanto na apresentação de achados clínicos, quanto nos que se fez necessário o tratamento, de forma que se mostra necessária a realização de avaliação inicial adequada de todos os recém-nascidos, em especial naqueles que possuem fatores de risco. Nível de evidência IV, Série de casos.

Descritores: Luxação Congênita de Quadril. Luxação do Quadril. Recém-nascidos.

Citation: Gonzalez FC, Fontes F, Maia GAS, Ferro JAS, Fortes DL, Leal DM. Orthopedic assessment of the hips in newborns after initial pediatric survey. Acta Ortop Bras. [online]. 2019;27(6):304-7. Available from URL: http://www.scielo.br/aob.

\section{INTRODUCTION}

Developmental Dysplasia of the Hip (DDH) is a condition that is expressed in different ways and at different ages, idiopathic, but associated with risk factors such as joint capsule laxity, family history, female sex, pelvic presentation during pregnancy or some ethnicities where they are most prevalent. ${ }^{1}$

In the newborn can be identified in the form of partial or complete displacement of the femoral head relative to the acetabulum. ${ }^{2}$ When diagnosed and treated early, there is a satisfactory progression in $95 \%$ of the cases with non-invasive treatments such as the Pavlik harness (developed by Arnold Pavlik [1902-1965], an orthopedist born in the former Czechoslovakia due to unsatisfactory treatment results at the time). Pavlik harness are the gold standard treatment up to six months of age, ${ }^{1}$ being a dynamic orthosis that allows the child to mobilize the lower limbs within certain limits, containing an anterior band that keeps the hips flexed, avoiding its extension and posterior bands limiting adduction. They should be initially used for twenty-four hours per day for about twelve weeks if stable hips, with weekly assessments for possible readjustments. After this period, progressive withdrawal is performed, taking four hours a day in the first two weeks, followed by eight hours daily between weeks two and four, and finally twelve hours a day until the eighth week, and is reevaluated after this period. ${ }^{3}$

All authors declare no potential conflict of interest related to this article.

The study was conducted at the Orthopedics and Traumatology Medical Residency of Santa Casa de Misericórdia de Ribeirão Preto, SP, Brazil. Correspondence: Av. Leais Paulistas 515, apto 235, Bairro Irajá, Ribeirão Preto, SP, Brazil. 14020-650. fellfelipe@gmail.com 
With late diagnosis and treatment there is worsening of prognosis and disastrous consequences as permanent functional limitations due to loss of joint congruity. 2,4

The incidence of DDH varies from 1:1000 to 3.4:100, more common in Native Americans, and also with higher rates in people who have a habit of wearing Swaddling bands (a kind of cloth used to wrap the buttocks and legs of newborn children with their hips in extension and adduction) or cradleboards, ${ }^{1}$ it is possible to get a greater number of findings when using the combination of clinical examination and ultrasonography. Depending on the used method, different incidences can be found; 1.4:1000 are reported for dislocation; 2.3:100 for isolated clinical findings; and abnormalities in USG of up to 8:100. Etiology is not well defined, but the predisposing factors are: ligament laxity (related to hormone, most important in females), intrauterine pelvic position, postnatal position with extended hips, racial preference (higher incidence in whites and Native Americans) , and primary acetabular dysplasia (unlikely). ${ }^{2}$ The most common pathological change in DDQ is the hypertrophy of the cartilaginous rim of the acetabulum in its upper, lower, and posterior portions. ${ }^{1}$ The examination of the hip in the newborn should be performed routinely in the nurseries. The diagnosis is basically clinical at first, through clinical tests such as those of Ortolani and Barlow, which are performed with the patient in the supine position and flexion of the hips and knees, the first is a reduction maneuver, in which the examiner will feel replacement of the dislocated hip after abduction and a pressure in the region of the great trochanter; the second one is a provocative maneuver in which a force will be performed in the inner region of the thigh and in the posterior direction, positive if the hip is dislocated. ${ }^{5}$ Conventional radiography has limited value and ultrasound is the ideal exam. ${ }^{6}$

In view of the amount of orthopedic assessments requested by the pediatrician for initial changes in the examination of the hip of the newborns, whether by clicks, subluxations or dislocations, this article was done with the intention of quantitatively ascertaining those in which these anomalies will evolve pathologically or if they are only cases of joint immaturity.

Treatment is challenging for both the pediatric and generalist orthopedist. The aim is early diagnosis associated with reduction of joint incongruity and stabilization of the hip in a safe position, which will be obtained according to the age of initiation of treatment, Pavlik harness up to six months of age is considered the gold standard, after this age other forms of treatment should be considered such as traction, closed or open reduction, or even femoral or pelvic osteotomies, depending on the age and severity of the condition. ${ }^{6}$

\section{Justification}

Newborns are usually evaluated only by Pediatricians, however, due to the incidence of clinical findings in approximately 2.3:100 live birth $^{2}$ and to the good prognosis of the DDH, when treated early, it is necessary to clarify the need for evaluation by the Orthopedist, in those who had changes in the initial physical examination.

Since there is little published scientific material on the subject to date, this may serve as an aid in the formation of a protocol, adapted to the local reality. This simple measure, associated with adequate screening, may reduce the number of serious sequelae due to diagnostic failure in initial care, also reducing the cost involved. ${ }^{2}$

\section{OBJECTIVES}

The objective of this study was to analyze and monitor patients previously selected by pediatricians from birth, with anamnesis in search of risk factors, initial clinical examination by using specific maneuvers, and complementary exams such as ultrasonography and radiography, to verify the incidence of hip pathologies that will develop in the first months of life.

\section{MATERIALS AND METHODS}

Made as a prospective cohort study started in the first days of life of the newborn, with analysis of patients with suspected DDH under evaluation by the pediatrician due to some alteration in their initial physical examination.

Data was collected from the patients, after authorization from the parents, with the standard informed consent term.

Next, the specific orientation of each case was given, with a three-week clinical and ultrasonographic reassessment, evaluating both hips by the Graf method, 1,2,4 and then choosing the appropriate treatment.

In cases in which there was no need for intervention, a final pelvic $\mathrm{x}$-ray was performed at 6 months old for documentation, analysis of ossification nuclei, and closure of the case.

After collecting the data, we analyzed the number of evaluations requested by the pediatricians, in which they considered the initial examination abnormal, and how many of them were shown to have dysplastic changes of the hips, which required any kind of surgical or conservative intervention.

During the study, 34 patients with 68 hips were selected, from birth, when asked for evaluation in the maternity ward, until the outpatient discharge or follow-up to the appropriate treatment.

This work was approved by the Ethics Committee of the Centro Universitário Barão de Mauá (CAAE: 92682418.4.0000.5378 / Parecer 2.808.501).

\section{RESULTS}

With an average of approximately 1300 live births annually at the institution, 1273 of which in the year of patient selection, 34 were selected with suspected dysplasia. The 34 patients were submitted to outpatient follow-up, separated by sex, 10 males, 24 females, with a female numerical superiority, consistent with the incidence of dysplastic pathologies. ${ }^{2}$ (Table 1)

During follow-up, patients who needed some type of intervention according to the GRAF method were selected by the ultrasonographic evaluation, according to the protocol already established in the literature ${ }^{1}$ and treated those classified as IIB or higher.

Of the 34 patients, only 02 were classified as needing treatment. We instituted the conservative treatment with the Pavlik harness for 8 weeks and observed a satisfactory result in both at the end of the treatment.

The remaining patients were discharged from the outpatient clinic or are under observation until the age of 6 months, when they should be discharged if there was no radiographic or clinical change to the examination.

Table 1. Selected patients.
\begin{tabular}{c|c|c|c|c|c|c|c|c}
\hline \multicolumn{3}{c|}{ Feminine } & \multicolumn{3}{c|}{ Masculine } & \multicolumn{3}{c}{ Total } \\
\hline \multicolumn{3}{|c|}{$\mathbf{2 4}$} & \multicolumn{3}{c|}{10} & \multicolumn{3}{c}{34} \\
\hline & I & IIA & IIB & IIC & IID & III & IV & Total \\
\hline Fem & 14 & 8 & 1 & 1 & 0 & 0 & 0 & 24 \\
\hline Mas & 6 & 4 & 0 & 0 & 0 & 0 & 0 & 10 \\
\hline Total & 20 & 12 & 1 & 1 & 0 & 0 & 0 & 34 \\
\hline
\end{tabular}

\section{DISCUSSION}

$\mathrm{DDH}$ can be defined as a spectrum of disorders that presents in different forms, variable according to age, with idiopathic cause, characterized by the inability to maintain the femoral head in the acetabulum, being related to predisposing factors such as: female sex; ligament laxity; prenatal pelvic presentation; postnatal positioning with hips in extension and adduction; and racial predilection, more common among Native Americans. ${ }^{1,2,7}$ 
It is a pathology that evolves over time. During embryogenesis, the development of the hip occurs from the seventh week of gestation, by forming the acetabulum from the contact with the femoral head and medial rotation of 90 degrees by the ninth week of gestation. In $\mathrm{DDH}$, normal structures gradually deteriorate for several reasons, especially poor fetal position (pelvic presentation) associated with ligament laxity. ${ }^{8}$ $\mathrm{DDH}$ is a progressive pathology associated with anatomical changes, which are usually reversible initially, (Figure 1) since the hips at birth are formed by cartilage and a fibrocartilaginous labrum, in addition to a flattened posterior-superior rhyme of acetabulum. In some cases, the unstable hip at birth reduces spontaneously and progresses satisfactorily with complete resolution of the changes. Others, however, will remain permanently displaced and other anatomical alterations will appear, consequently there will be abnormal radiological parameters. ${ }^{1}$ (Figure 2)

Early diagnosis and treatment is imperative for the good prognosis of patients. ${ }^{1}$ As the hip remains displaced, secondary barriers to reduction appear, as the thickening of the acetabular pulvinar and

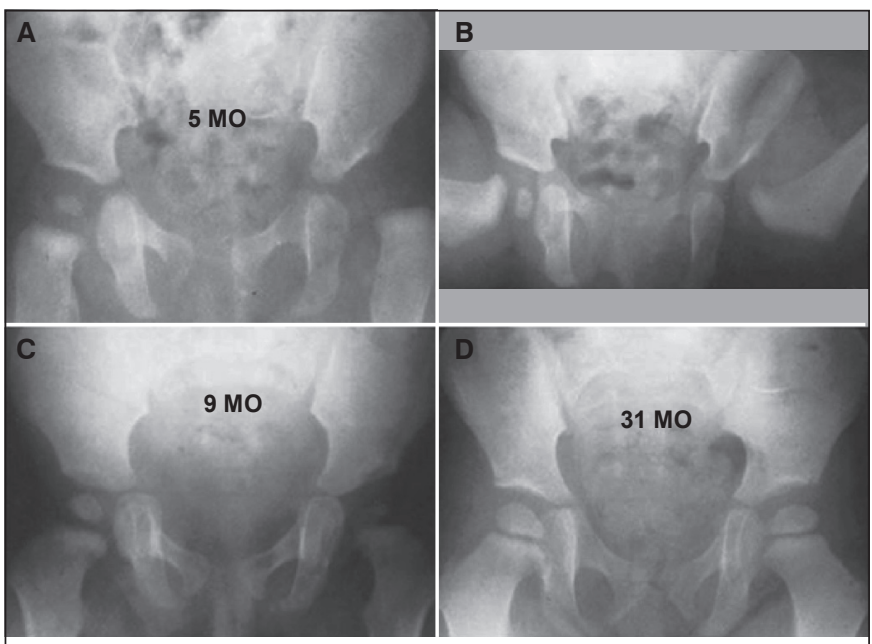

Source: Weinstein SL, Flynn JM. Lovell and Winter's Pediatric Orthopaedics. 7 ed. Philadelphia: Lippincott Williams \& Wilkins; 2014.

Figure 1. Follow-up of patients with left dysplastic hip, from the 5th to the 31 st month of life. In which there is a progressive improvement of the Acetabular Index.

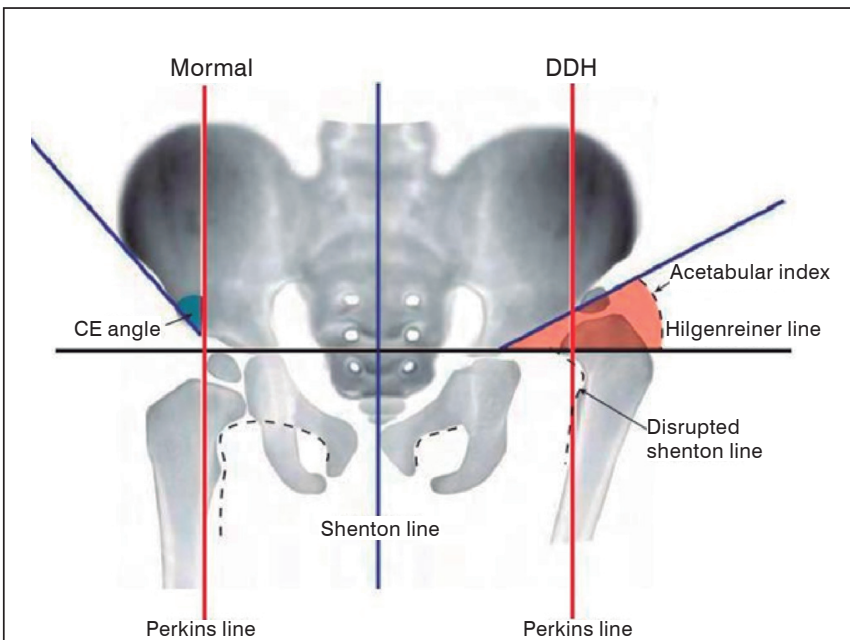

Source: Weinstein SL, Flynn JM. Lovell and Winter's Pediatric Orthopaedics. 7 ed. Wolter Kluwer; 2014.

Figure 2. Radiologic Parameters: Wiberg CE Angle; Perkins Line; Shenton Line; Hilgenreiner Line; Acetabular Index. the round ligament lengthens and thickens; the anatomical deformity of the lower capsule, which contracts and narrows its diameter in relation to the femoral head (hourglass deformity). In addition to these described changes, the shortening of the pelvis-femoral muscles in chronic cases caused by femoral ascension should be remembered. ${ }^{2}$ Classically, instability was defined by the positivity of the Ortolani and Barlow tests, but this definition is currently challenged because of some clinically stable patients who have sonographic changes. Due to inconsistent data, the rate of those who will have spontaneous resolution is unknown.

The "click" that was considered for the selection of study patients, although most of the time it has no clinical significance, has an important correlation with some ultrasonographic changes. It is also worth mentioning that the reassessment of all patients is important due to some instabilities occurring only after the neonatal period. Patients' treatments were guided with Ultrasonographic aid, taking into account the angle between the bony roof and the cartilaginous roof of the acetabulum, (Figure 3) using the GRAF method, in which treatment was instituted in those classified with Ilb or higher, since already are considered as having abnormal hip. (Table 2)

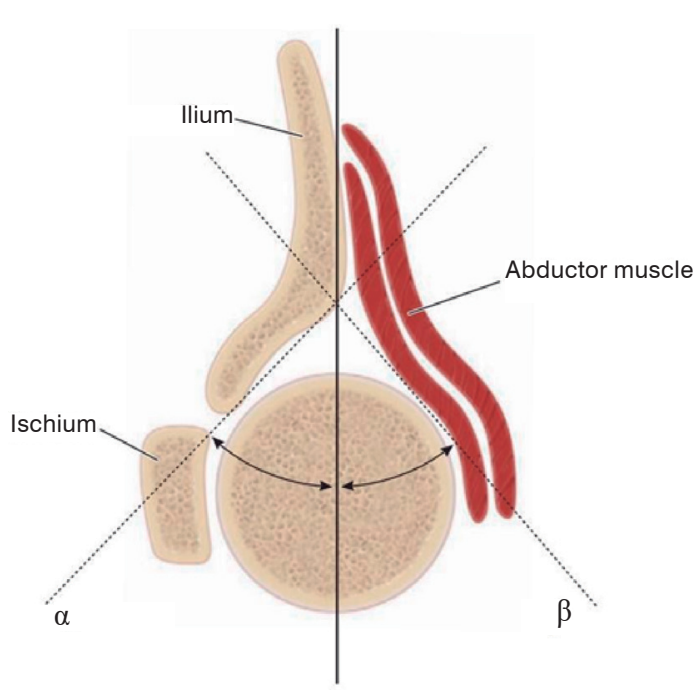

Source: Herring JA. Tachdjian's Pediatric Orthopaedics: From the Texas Scottish Rite Hospital for Children. 5 ed. Philadelphia: Elsevier Saunders; 2013.

Figure 3. Alpha and Beta angle measurement.

Table 2. Graf Classifcation System of Developmental Dysplasia of the Hip on the Basis of the Sonographic Angles of the Hip.

\begin{tabular}{c|c|c|c|c}
\hline Class & Alpha Angle & Beta Angle & Description & Treatment \\
\hline \multicolumn{5}{c}{ Standard Classification } \\
\hline I & $>60^{\circ}$ & $<55^{\circ}$ & Normal & None \\
\hline II a & $50^{\circ}-60^{\circ}$ & $55^{\circ}-77^{\circ}$ & Immature $(<3$ months $)$ & Observation \\
\hline II b & $>50^{\circ}-60^{\circ}$ & $>77^{\circ}$ & $>3$ months & Pavlik harness \\
\hline II c & $43^{\circ}-49^{\circ}$ & $>77^{\circ}$ & Acetabular deficiency & Pavlik harness \\
\hline II d & $43^{\circ}-49^{\circ}$ & $>77^{\circ}$ & Everted labrum & Pavlik harness \\
\hline III & $<43^{\circ}$ & $>77^{\circ}$ & Everted labrum & Pavlik harness \\
\hline IV & Unmeasurable & Unmeasurable & Dislocated & $\begin{array}{c}\text { Pavlik harness/closed } \\
\text { vs. open reduction }\end{array}$ \\
\hline \multicolumn{5}{c}{ Simplified Classification } \\
\hline I & $>60^{\circ}$ & $<55^{\circ}$ & Normal & None \\
\hline II & $43^{\circ}-60^{\circ}$ & $55^{\circ}-77^{\circ}$ & Delayed ossification & Variable \\
\hline III & $<43^{\circ}$ & $>77^{\circ}$ & Lateralization & Pavlik harness \\
\hline IV & Unmeasurable & Unmeasurable & Dislocated & $\begin{array}{c}\text { Pavlik harness/closed } \\
\text { vs. open reduction }\end{array}$ \\
\hline
\end{tabular}

Source: Herring JA. Tachdjian's Pediatric Orthopaedics: From the Texas Scottish Rite Hospital for Children. 5 ed. Philadelphia: Elsevier Saunders; 2013. 
An average of 2.67:100 of live births that showed abnormal clinical findings was observed and, thus, compatible with the data described in the specialized literature.

It is also worth noting that in none of the patients evaluated, the Ortolani and Barlow tests were positive, as described in the literature, since they are considered as low sensitivity tests, despite good specificity. As the study was made with newborns, all treatments were performed using the Pavlik harness, a high-efficiency and low-cost method. ${ }^{9}$ Satisfactory results were obtained in the patients until the conclusion of the study. The remaining cases remain in outpatient follow-up, progressing satisfactorily until then.

If started after 6 months of age, the treatment will consist of more complex methods, from traction to the open reduction of dislocation. Performing pelvic osteotomy is a possibility, especially if performed after 18 months of life. Thus, the importance of an evaluation as early as possible, which will generate the diagnosis and early treatment, improving the quality of life and reducing costs for the patient. ${ }^{2,10}$

\section{CONCLUSION}

It could be observed that despite the low workload and the low importance usually presented in medical courses related to orthopedic specialty, the data obtained is consistent with the literature, considering the clinical findings that generated the request for evaluation, and those who should receive specific treatment.

In the literature it is described that the Pavlik suspensory has good results in approximately $97 \%$ of those with Graf lower than III, who receive early treatment. In the 2 cases presented, satisfactory results were observed at the end of the treatment, then the efficacy of the method was verified, despite the low sampling.

Thus, the importance of performing early evaluation of the newborns, both in the clinical and ultrasonographic areas, was observed, despite the negative Ortolani and Barlow tests, 2 cases were diagnosed, received the early treatment and thus severe sequelae were avoided in the future. Noninvasive, low-cost treatment plays an important role in avoiding considerable expense with hospitalizations and corrective procedures.

AUTHORS' CONTRIBUTIONS: Each author contributed individually and significantly to the study. FF (0000-0001-9545-685X)*: manuscript writing, data collection, and manuscript review; GASM (0000-0002-9043-0340)* manuscript writing and comprehensive analysis of the intellectual concept; FCG (0000-0002-9324-2409)* analysis of intellectual concept; DML (0000-0001-5355-1832): manuscript writing, comprehensive analysis of the intellectual concept, and manuscript review; DLF (0000-0002-1847-4621)*: comprehensive analysis of the intellectual concept; JASF (0000-0002-3391-1754)*: comprehensive analysis of the intellectual concept, data collection, and manuscript review. ${ }^{*} \mathrm{ORCID}$ (Open Researcher and Contributor ID).

\section{REFERENCES}

1. Weinstein SL, Flynn JM. Lovell and Winter's Pediatric Orthopaedics. 7 ed. Philadelphia: Lippincott Williams \& Wilkins; 2014.

2. Herring JA. Tachdjian's Pediatric Orthopaedics: From the Texas Scottish Rite Hospital for Children. 5 ed. Philadelphia: Elsevier Saunders; 2013.

3. Guille JT, Pizzutillo PD, MacEwen GD. Developmental dysplasia of the hip from birth to six months. J Am Acad Orthop Sur. 2000;8(4):232-42.

4. Paton RW, Choudry Q. Developmental dysplasia of the hip (DDH): diagnosis and treatment. Orthopaedics And Trauma. 2016;30(6):453-60.

5. Sadler TW. Langman's medical embryology. 14 ed. Philadelphia: Wolters Kluwer; 2018.

6. Mubarak S, Garfin S, Vance R, McKinnon B, Sutherland D. Pitfalls in the use of the pavlik harness for treatment of congenital dysplasia. subluxation and dislocation of the hip. J Bone Joint Surg Am. 1981;63(8):1239-48.

7. Wedge JH, Kelley SP. Strategies to Improve Outcomes from Operative Childhood Management of DDH. Orthop Clin North Am. 2012;43(3):291-9.

8. Guarniero R. Displasia do desenvolvimento do quadril: atualização. Rev Bras Ortop. 2010;45(2):116-21.

9. Clarke NMP, Castaneda P. Strategies to Improve Nonoperative Childhood Management. Orthop Clin North Am. 2012;43(3):281-9.

10. Seringe R, Bonnet JC, Katti E. Pathogeny and natural history of congenital dislocation of the hip. Orthop Traumatol Surg Res. 2014;100(1):59-67. 